\title{
Study on the Online Teaching Practices of Enterprise Resource Planning Course
}

\author{
Pengyu Zhu ${ }^{1, *}$ \\ ${ }^{1}$ School of Management Engineering, Xuzhou University of Technology, Xuzhou, Jiangsu 221000, China \\ *Corresponding author. Email: 470291629@qq.com
}

\begin{abstract}
There are great differences in teaching content design and interaction between online teaching and offline teaching. In order to obtain better teaching and learning effect, it is necessary to reconstruct teaching activities, teaching environment, learning and evaluation methods. Based on the analysis of the characteristics of ERP course, this paper discusses how to effectively use the course platform and live broadcast software for online teaching. This paper take sales management as an example, redesigns the complete teaching process and provide reference for further improving the teaching quality and teaching effect.
\end{abstract}

Keywords: online teaching, teaching model, enterprise resource planning

\section{INTRODUCTION}

Online teaching is a new teaching model that uses computer and network technology, relies on professional course teaching platform or online live software for real-time interaction. It is an effective supplement to the traditional classroom teaching model. Due to the space-time distance between teachers and students in the online teaching model, it is difficult to keep the classroom order and know students' learning state. At the same time, it is also limited by platform technology and network transmission stability, so online teaching has been difficult to completely replace offline teaching.

Because of the epidemic in the world in 2020, many colleges and universities have to choose online teaching. Online teaching from the original supplement to the traditional teaching model has become the main teaching method. For teachers, the biggest challenge is the need to change teaching strategies and teaching methods, to change the past teaching habits and to change teaching concepts[1].

\section{CHARACTERISTICS OF ENTERPRISE RESOURCE PLANNING COURSE}

The course of enterprise resource planning (ERP) is an applied course with close relation between theory and practice. ERP is a new modern enterprise management model, which is based on the management idea of supply chain, plans and controls all resources of the enterprise on the basis of information technology, and provides decision support and management platform for the enterprise. Mastering the basic knowledge of this course can not only help students get familiar with the operation process and all business processes of various departments of an enterprise, but also enhance their professional competitiveness. As a result, many university management majors have listed ERP as a compulsory course in their teaching plans.

Because the ERP system contains the business process of the whole enterprise and the software function is complex, the classroom teaching should focus on the teaching of ERP principle and the complete business process, the teaching content is diverse and practical. However, the traditional offline teaching model does not adapt to this characteristic. It often pays attention to imparting knowledge and ignores the cultivation of practical ability. Students often accept knowledge passively, and their practice and hands-on ability is poor, so as to weaken the competitiveness and social adaptability.

ERP courses are generally composed of theoretical courses and experimental courses, in which the experimental part accounts for a small proportion of class hours. Teachers demonstrate the operation process of the software, and students follow the drill in the experimental class. This will make it difficult for students to know much about the operation process of 
the enterprise, and understand the operation principle of ERP well, so the teaching effect is not obvious.

\section{THE CHOICE OF TEACHING PLATFORM}

Online teaching is "learner-centered" as the educational concept[2].Compared with traditional teaching, the communication model of online teaching is different. There are great differences in teaching content design, teaching process interaction, teaching effect evaluation, students' academic evaluation and so on. Different teaching platforms and live broadcasting tools will directly affect the teaching effect. Therefore, according to the characteristics of the course, teachers need to choose an appropriate online teaching platform, quickly familiarize software operation, reasonably choose and edit online teaching content, enrich the forms of interaction, build online exercise library, reconstruct academic evaluation elements, and realize the "learner-centered" online teaching model.

At present, there are many platforms for online teaching, such as China University MOOC, Chaoxing learning link, rain classroom, Tencent classroom, wisdom tree, DingTalk, Tencent Meeting, QQ group classroom, etc.[3]Teachers can choose different online teaching platforms according to the characteristics of courses and teaching needs.

Considering the stability and fluency of the platform, and combined with the characteristics of the course and the needs of students, the enterprise resource planning course finally chooses Tencent classroom, Chaoxing course platform and QQ group to jointly carry out network live teaching. Tencent classroom has comprehensive functions and good stability. It has the functions of screen sharing, playback and Lianmai speech. The teaching resources of Chaoxing course platform are rich. Teachers can upload teaching ppt, teaching video, course related materials, experimental tasks and other contents. Students can preview, ask questions and exchange, and complete after class exercises. QQ group as a supplementary way, also has the function of file sharing and question exchange. Therefore, teachers can monitor students' learning progress and learning effect in real time, restore the reality of the classroom as much as possible, so as to achieve better teaching effect.

\section{PRACTICE PROCESS OF ONLINE TEACHING}

\subsection{Overall design of teaching content}

Teaching material is the carrier of course content. In order to ensure integrity and scientificity of course knowledge system in online teaching, the contents of the existing ERP textbooks are carding and integrating. The course content is mainly divided into 10 topics, such as "ERP overview", "basic data", "sales management", "purchase management", "inventory management", "master production schedule", "material requirement planning", "capacity requirement planning", "workshop management and financial management" and "ERP implementation".

In the learning process of each topic, we should help students enter the self-study state and enhance their learning enthusiasm through preview, discussion and communication, and teamwork. Therefore, teachers should make full use of the teaching resources in the network course platform. The PPT, teaching video, course related materials, experimental tasks and other contents of classroom teaching can be released to the course platform in time before class, and some online learning resources can also be screened and recommended. Students can learn and ask questions through the platform, and communicate with teachers about the learning situation. They also can upload homework, lecture materials and learning summary to the course platform after class. Teachers should give feedback in time.

\subsection{Specific teaching practice process}

\subsubsection{Before class}

Sufficient preparation before class is the premise to ensure the teaching quality and teaching effect[4]. Before each topic learning, teachers should first make clear the learning task and set teaching objectives. For example, in the "sales management" project, students can master how to deal with ordinary sales business through ERP software and relevant theoretical knowledge according to the work scenarios set by teachers.

Teachers prepare teaching plans, courseware and record teaching videos in advance and upload them to the course platform and QQ group. The contents of courseware and teaching video mainly include the business of sales management, the role of sales management, the business process of sales management, the relationship between sales management and other systems, the main functions of sales management module, how to deal with ordinary sales business, how to deal with cash settlement business, how to deal with sales return business. Because the teaching video time is short, it is very important to make the focal points stand out, the theme clear, the language concise and attractive.

Before class, students should be urged to study independently. They watch the courseware and teaching video of "sales management" in advance. If they have questions or don't understand, they can discuss and communicate with teachers and students through the course platform and QQ group. In this case, students can 
freely arrange their own learning time and rhythm, and can watch the courseware and teaching video repeatedly. This can effectively cultivate and improve students' self-learning ability. Teachers can also have a clear idea of the weak links of students in the learning process, timely adjust the class content and teaching activity design, and carry out targeted explanation.

\subsubsection{During class}

Online teaching requires teachers to add more interactive links in the teaching design to give students a sense of substitution and live[5].Teachers design the teaching activities of online courses in the form of discussion and experience, and carry out real-time interaction between teachers and students through the live software or QQ group, so as to solve the problems and doubts in the learning process of students, explain the key and difficult points of the course in detail, and carry out diversified assessment. In the process of online teaching, teachers should choose appropriate methods for discussion and communication, so as to effectively enhance the efficiency of online teaching. The whole classroom interaction is divided into the following stages:

In the first stage, the pre-recorded video is played. With the help of sales business flow chart, students can basically master the business process of ERP software sales management module. The duration of video should be controlled within 10 minutes. After watching, the teacher can explain some key points and difficulties of the sales content in combination with the problems raised by the students in the autonomous learning before class. Some topics can also be explained by students and supplemented by teachers.

In the second stage, the students draw the business processing flow chart of the sales management based on the preparation before class and the teacher's explanation, and mark out the specific tasks to be completed for each job. Combined with the simulation scenario given by the teacher - a sales business case of a company, the students discuss in groups and brainstorm how to solve practical problems.

In the third stage, students use ERP software to carry out the operation experiment of sales management module. Taking SAP GBI software as an example, the specific process is as follows: running SAP SD (sales and distribution) module, create new customers and contact person, create customer inquiry, create quotation create sales order referencing quotation and check stock status, start delivery process and check stock status, pick materials on delivery note, post goods issue and check stock status, create invoice for customer, view billing document and customer Invoice, post receipt of customer payment, review document flow. In this process, each student independently completed the process of sales business, which can make them better understand the whole process of enterprise sales business operation and the responsibilities of each part. Of course, the experimental operation can also be carried out in groups. Each group member plays the different role in the ordinary sales business operation, such as sales representative, sales supervisor, warehouse supervisor, financial supervisor, etc.

After all operations are completed in SD module, everyone can query the complete business process, as shown in the figure below.

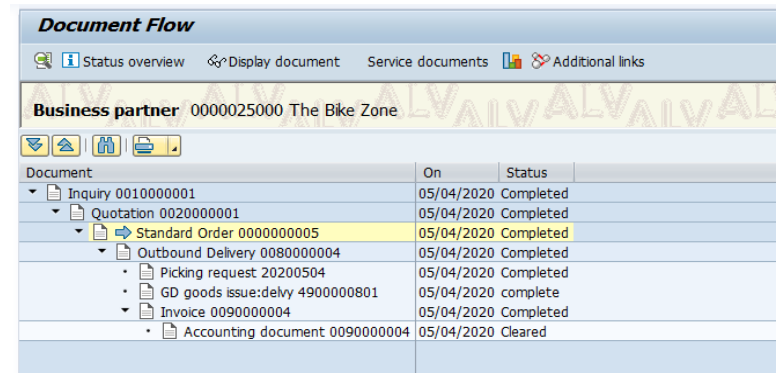

Figure 1 Document Flow

Students can check whether the sales business has been completed and whether there are errors or omissions by reviewing document flow. Teachers can also guide students according to the document flow.

In the final stage, in the question session, students can use QQ group and Tencent classroom screen sharing function to report the completion of the sales business process experiment to teachers, ask how to solve the problems in the experimental process, and what doubts exist in the theoretical knowledge learning, and then the teachers can solve the problems in teaching practice together with students.

\subsubsection{After class}

After class time is mainly for students to review and summarize, further summarize the opinions in the classroom discussion, reflect on the experimental operation process and write the experimental report. Pay attention to teaching evaluation after class[6].Teachers should integrate the data of students' learning behaviour fed back by the platform, answer questions online, and evaluate according to the process factors such as students' attendance, PPT production, team cooperation, number of discussions and speeches, experimental process, report writing, etc. At the end of each course, teaching reflection should be carried out in time to sum up experience and improve teaching methods for the second teaching, communication and guidance should be given to individual students who have not completed their learning tasks. 


\section{CONCLUSION}

The sudden epidemic situation catalyses the frequent use of online teaching model in many colleges and universities, and improves the acceptance of it, but also highlights some disadvantages of online teaching in this process. Therefore, colleges and universities need to further optimize the online course resources, continue to monitor the online teaching to ensure the quality of teaching, and improve the ability of teachers' online teaching. It is necessary to strengthen the training of teachers in information technology, related systems and software operation, so that teachers can better apply it to education practice, and strive to achieve the reform and innovation of classroom teaching methods. Teachers also should change the teaching concept, enhance the enthusiasm of students' autonomous learning, and improve the effect of online learning.

\section{REFERENCES}

[1] D.G.Wu, W.Li.The stage characteristics of large scale online teaching in Chinese Universities-An empirical study based on the questionnaire survey of students, teachers and educational administrators- An empirical study based on the questionnaire survey of students, teachers and educational administrators. Journal of East China Normal University, Educational Sciences, (7) (2020)1-30.DOI:

https://doi.org/10.16382/j.cnki.1000-

5560.2020 .07 .001

[2] X.P.Hu, Z.X.Xie. Analysis of the advantages and challenges of online teaching in Colleges and Universities under the epidemic situation. Research on Higher Education in China, (4) (2020)18-22. DOI:https://doi.org/10.16298/j.cnki.10043667.2020.04.04

[3] L.Zhou, Y.L.Cheng, F.L.Hu. Online teaching exploration of "interchangeability and technology measurement" based on "superstar Learning + Tencent conference + QQ group". Science and education guide,(6) (2020)106-107. DOI:

https://doi.org/10.16400/j.cnki.kjdkz.2020.06.051

[4] X.L.Zhu , W.L.Yang, Y.F.Zhang, D.Wu. Practice of online teaching based on "Tencent classroom + Learning link". Science and technology vision,(2) (2021)74-76.

DOI: https://doi.org/10.19694/j.cnki.issn20952457.2021.02.33

[5] Y.Zhao, B.L.Liu, Z.X.Wang. Study on feedback interactive online teaching mode combining Tencent classroom and rain classroom. computer education, (2)(2021)13-21. DOI: https://doi.org/10.16512/j.cnki.jsjjy.2021.02.005

[6] L.Bai.Online innovative classroom teaching design based on Blended Learning. Technology and innovation,(22)(2020) 89-91. DOI:

https://doi.org/10.15913/j.cnki.kjycx.2020.22.037

[7] Z.B.Feng.Research on ERP Experimental Teaching Based on SAP. Management informatization in China,22(17)(2019)223-225.

[8] X.C.Wang,P.P.Li,X.X.Qi, Z.Y. Wang.Construction of large scale collaborative online teaching systemtaking large scale collaborative online teaching in Zhengzhou University as an example. Journal of Higher Education,(7) (2021)13-17. 